\title{
OBSERVING WAVE PACKETS GENERATED BY SOLAR TERMINATOR IN TEC DURING TYPHOONS
}

\author{
I.K. Edemskiy \\ Institute of Solar-Terrestrial Physics SB RAS, Irkutsk, \\ Russia, ilya@iszf.irk.ru
}

\author{
A.S. Yasyukevich \\ Institute of Solar-Terrestrial Physics SB RAS, Irkutsk, \\ Russia, annpol@iszf.irk.ru
}

\begin{abstract}
In this work, we study ionospheric disturbances excited by the passage of the solar terminator (ST) during tropical cyclones, using total electron content (TEC) data. We have considered 16 intense tropical cyclones (typhoons) that acted in the northwest of the Pacific Ocean near the territory of Japan. We analyze two-dimensional distributions of the number of registered wave packets (WPs) depending on various parameters: local time, WP maximum amplitude, and distance to typhoon. It is shown that in most cases the maximum number of WPs is observed at a distance less than 500 $1500 \mathrm{~km}$ from the typhoon center and near the time of evening solar terminator passage. For typhoons occurring during autumn periods, the maximum number of WPs is recorded at daytime, and, apparently, is not
\end{abstract}

associated with ST. Distributions of the number of WPs depending on their amplitude have a similar form for all the cases considered, with a maximum of about 0.2 TECU. At the same time, for some typhoons there are a large number of WPs with amplitude up to 0.6-0.8 TECU, which is significantly higher than WP amplitudes under quiet conditions. We briefly discuss the mechanism of possible interaction between ionospheric disturbances caused by two different sources (tropical cyclones and ST passage).

Keywords: wave packets, TEC, typhoon, solar terminator, ionospheric disturbances, GNSS.

\section{INTRODUCTION}

The ionosphere is a complex dynamic system whose behavior is associated not only with changes in helioand geomagnetic factors, but also with neutral atmosphere conditions. The study of interrelated processes occurring in Earth's lower and upper atmosphere is therefore one of the priorities in geophysics and meteorology. It has been established that under quiet geomagnetic conditions, ionospheric electron density variations associated with the influence of meteorological factors may amount to $35 \%$ of the background ionization [Forbes et al., 2000].

The main mechanism of disturbance energy transfer from the troposphere to ionospheric heights is represented by internal atmospheric waves of various scales: tides, planetary waves, internal gravity waves (IGWs) [Lastovicka, 2006]. Under certain conditions, IGWs can reach ionospheric heights, causing electron density disturbances, which are detected as traveling ionospheric disturbances (TIDs) [Kazimirovsky, 2002]. According to the literature, among IGW sources in the lower neutral atmosphere are jet streams, tsunami, storms, tropical cyclones, etc.

Tropical cyclones (TCs) are powerful vortex structures in the troposphere whose evolution is accompanied by generation of IGWs of different scales. Several experimental and theoretical studies have shown that over TC areas in the mesosphere and lower thermosphere there are IGWs with periods from 2 min to 6 hrs and spatial scales from 15 to $1000 \mathrm{~km}$ [Chane-Ming et al., 2002; Pfister et al., 1993; Kim et al., 2005; Kuester et al., 2008]. Wave disturbances with periods from 2 to 90 min over TC areas have also been detected in the electron density of the ionosphere, using different radiophysical methods [Xiao et al.,
2007; Bertin et al., 1975; Huang et al., 1985; Bishop et al., 2006; Polyakova, Perevalova 2011, 2013]. A number of features of these disturbances have been identified: their intensity is maximum when cyclone air masses flow around the coastline and during rapid changes of wind velocity in TC [Xiao et al., 2007; Zakharov, Kunitsyn, 2012]. Bertin et al. [1975] showed that TIDs propagated predominantly in the direction opposite to the background wind at the ionospheric height. This indicates their relation to IGWs [Medvedev et al., 2017].

Note that intense TCs which have a wind speed $V>74$ knots $(1$ knot $=1$ nautical mile/hr or $0.5144 \mathrm{~m} / \mathrm{s}$ ) and occur in northwestern Pacific Ocean is also called typhoons.

Unlike TCs, solar terminator (ST) passage is a regular source of wave disturbances in the atmosphere and ionosphere. Earlier studies of ionospheric conditions in the region of ST passage [Hines, 1960; Francis, 1974] have shown that ST passage causes wave generation as well as instabilities and fluctuations in ionospheric plasma. This led to a number of studies of ionospheric parameters during ST passage [Mishin et al., 1991; Somsikov, Ganguly, 1995; Galushko et al., 1998].

Ionospheric sounding by GNSS (Global Navigation Satellite Systems) signals enabled Afraimovich et al. [2003; 2009a, 2009b] to discover that ST passage is accompanied by generation of medium-scale ionospheric disturbances of a special type - wave packets (WPs) manifesting themselves as narrowband oscillations of the total electron content (TEC). A model of generation of magnetohydrodynamic (MHD) plasma disturbances in the ionosphere-plasmasphere system, which can explain observed TEC oscillations, has been proposed and 
theoretically justified. This model assumes that ST passage leads to generation of currents in the conductive ionospheric layer, which produce slow magnetic sound waves. A mechanism has also been proposed for transferring the generated ST disturbances along magnetic field lines to another hemisphere [Leonovich et al., 2010]. Further studies [Edemskiy, Yasyukevich, 2011] have shown that TEC disturbances associated with ST passage may have a more complex structure, as, apparently, a superposition of ionospheric plasma oscillations caused by the influence of not only MHD waves but also of gravity waves.

Since TCs and ST passage generate atmospheric waves of different types but with similar time scales, it is assumed that if these phenomena exist simultaneously in the ionosphere, the disturbances caused by these sources may interact. Thus, Belyaev et al. [2015] using satellite measurements of electron density have shown that ionospheric conditions in the vicinity of ST change during periods of intense TC passage over the land surface. The authors however used a limited amount of data, which did not allow reliable identification of the presence of possible interaction.

Polyakova and Yasyukevich [2016] have presented spatial maps of TEC variations during the HALONG typhoon, which clearly show that the amplitude of wave disturbances, caused by ST passage, was higher than that on stormless days. A similar result was obtained by Chou et al. [2017a] for the NEPATRAK typhoon. The authors observed a distinct presence of MHD waves, which we think were driven by ST passage (they have specific wavefront slope and time of appearance), and cyclone-associated concentric IGWs. The authors concluded that the wave disturbances interact and proposed a possible mechanism of this interaction. In our opinion, they misidentified waves generated by ST passage; therefore the proposed mechanism is not appropriate for this case.

Thus, the question about possible TC impact on the intensity and structure of TIDs generated by ST passage requires a more careful analysis involving large observational statistics. In this paper, using GNSS ionospheric sounding data, we analyze TIDs, observed during ST passage, in periods of 16 tropical cyclones of different intensity.

\section{DATA}

\section{AND PROCESSING METHOD}

Our study uses data on TEC variations in the ionosphere, obtained from dual-frequency phase GPS/GLONASS measurements. Trajectories of the typhoons selected for the study were located in northwestern Pacific Ocean near Japan. This allows us to use data from the unique network of GNSS receivers Geonet [http://terras.gsi.go.jp], which comprises more than 1200 stations. The great number of receivers in the region enables us to trace ionospheric variations with high space-time resolution.

Using initial data, we analyze TEC variations for the presence of wave packets. Search for WPs is conducted automatically with the method described in detail in [Yasyukevich et al., 2013]. Briefly, the analysis consists of several stages.
1. Converting oblique TEC values $I_{\mathrm{s}}(t)$ into an equivalent vertical TEC value $I(t)$ according to Klobuchar's formula [Klobuchar, 1986].

2. Filtering the resulting TEC series by the moving average method in a range 2-20 min, selected from the observed WP periods (12-17 min) [Edemskiy et al., 2011].

3. We select WPs according to two criteria. First, we select TEC variations whose standard deviation (SD) exceeds a given threshold of 0.05 TECU. Then, for each of the filtered series, we calculate an amplitude Fourier spectrum. Using the obtained spectrum, we check the fulfillment of the narrow-band (quasi-monochromic) condition of TEC variations to find variations with a relatively narrow spectrum. If an initial series satisfies these conditions, such an event is classed as WP.

4. To determine the duration of the recorded WP, in each case we find the envelope from the level of 0.5 of the maximum amplitude of WP and calculate its duration. Then, we take the time of WP registration to be the middle of the interval when the amplitude of the envelope exceeds 0.5 of the maximum.

To analyze the relationship between observed disturbances and ST passage, we use the system of terminator local time (TLT) proposed in [Afraimovich et al., 2009b]. The method involves the transition to the time $d T=t_{\mathrm{obs}}-t_{\mathrm{st}}$, where $t_{\mathrm{obs}}$ is the time of disturbance registration at a point, $t_{\mathrm{st}}$ is the time of ST passage above this point, which is determined for a height of $300 \mathrm{~km}$.

Systematizing WP observation data, we can plot two-dimensional distributions of the number of WPs and observe their dependence on various parameters such as time, amplitude, and distance to typhoon. Figure 1, $a$ shows the general distribution of the number of WPs in 2008-2016 depending on the distance to the typhoon eye (center) and on the WP amplitude. The distance is determined as a great-circle arc between the WP registration point and the typhoon center location. We assume that the possible impact of the typhoon on WP generation should decrease with distance, so the WPs registered more than $3000 \mathrm{~km}$ away from the typhoon center are excluded from consideration. Thus, to plot the distributions, we use data only on $38.6 \%$ of the total number of WPs over the given period.

The analysis of the dependence of the number of registered WPs on the distance from the typhoon eye shows that most of them occur at a distance 2000-2500 km (Figure 1, a). It should be noted that, approaching the coastline, a typhoon exhibits a tendency to decay, and hence the period during which the typhoon is near the land (i.e. close to most GNSS stations) is much shorter than the period during which it is over the ocean. By determining the distance from each network station to the typhoon eye with a one-hour interval throughout the observation time, we plot the distribution of these distances (Figure 1, b) whose peak is at 2000-2500 km. Thus, the number of WPs in this range is larger only due to the great number of observations with such distances. The use of weights for each distance, inversely to the resulting distribution (Figure $1, b$ ), would be more representative. Figure 1, $c$ shows the weighted distribution of the number of WPs. Using the weights, we can talk only 
about the relative number of registered WPs, but not about specific distance-dependent values, therefore the color scale on normalized distributions is relative and can be omitted. Figure 1, $c$ shows that the introduction of normalization yields on average identical amplitude distributions for all distances. The presence of local enhancements $(0$, $1000,2500 \mathrm{~km}$ ) is likely associated with features of the selected normalization. The average WP amplitude weakly depends on the distance to the typhoon center and is about 0.15-0.2 TECU, which is consistent with previous studies [Afraimovich et al., 2009b].

\section{CHARACTERISTICS OF THE TYPHOONS UNDER STUDY}

To analyze the possible joint impact of the solar terminator and typhoons on the ionosphere, we have selected 16 tropical cyclones for 2008-2016, occurring near Japan. We have chosen intense typhoons of the second category (the wind speed $V>96$ knots). Data on evolution and trajectories of the typhoons have been obtained from the NOAA Environmental Satellite, Data and Information Service [http://rammb.cira.colostate.edu]. Periods of activity of the typhoons and maximum velocities for each of the typhoons are listed in Table.

Figure 2 shows trajectories of the eye of each of the selected cyclones from formation to decay. Markers denote the position of the typhoon eye every three hours. The marker size corresponds to the sustained wind speed in a typhoon at each specific point. The diameter of the marker in legend corresponds to 100 knots. It is seen that the region of typhoon formation in northwestern Pacific Ocean is within $10-15^{\circ} \mathrm{N}$ and $135-150^{\circ} \mathrm{E}$. During their evolution, the typhoons move northwestward, and then in most cases their trajectories turn and the typhoons move northeastward, reaching the territory of Japan, where Geonet GNSS receivers are located.

An exception are HAGUPIT, RAMMASAN-14, and MERANTI tropical cyclones with trajectories below $20^{\circ} \mathrm{N}$; i.e., these typhoons occurred not closer than at $\sim 1500 \mathrm{~km}$ from the Japanese islands.

\section{ANALYSIS OF CHARACTERISTICS OF RECORDED WPS}

Using the above detection method, we analyze distributions of the number of WPs in TEC during the selected TCs depending on WP amplitude, distance to TC centers, and time of WP detection. The total number of WPs registered during each typhoon is given in Table. As mentioned above, WPs detected farther than 3000 $\mathrm{km}$ from the typhoon eye are excluded from consideration. It can be seen that the greatest number of WPs occur in summer (summer periods are highlighted in gray in Table), which is consistent with previous observations [Edemskiy et al., 2011]. In summer, about 150 250 thousands of WPs were on average registered during one typhoon. An exception are the NAKRI and NAMTHEUN typhoons, which occurred in the late spring and early autumn respectively. In spring and autumn, the generation of WPs by the evening ST is less effective than in summer [Afraimovich et al., 2009b]. In addition, during NAMTHEUM geomagnetic conditions were disturbed, which could also affect the efficiency of generation. In spring and autumn, efficiency of WP generation in the ionosphere decreases markedly, which is probably related to changes in orientation of the ST line relative to magnetic field lines. The number of WPs in these periods is $\sim 50-100$ thousands. Pay special attention to cases when the total number of detected WPs is much smaller. So, for RAMMASAN-08, HAGUPIT, JANGMI, and NAMTHEUM, the total number of registered WPs does not exceed 20 thousands. Statistical results for these typhoons are the least representative, but they may suggest that a typhoon destructively affects the resonance system responsible for WP generation.

To examine the relationship between WP generation and typhoon passage, we plot distributions of the number of WPs as function of distance to the typhoon eye and local time of the evening ST (Figure 3). We ignore distributions for the local time of the morning ST because the generation of WP during its passage in the season under study is much weaker [Edemskiy et al., 2011]. The distributions are plotted taking into account the weighting function (Figure 1, b), arranged chronologically, and marked with the same letters as typhoons in Table.
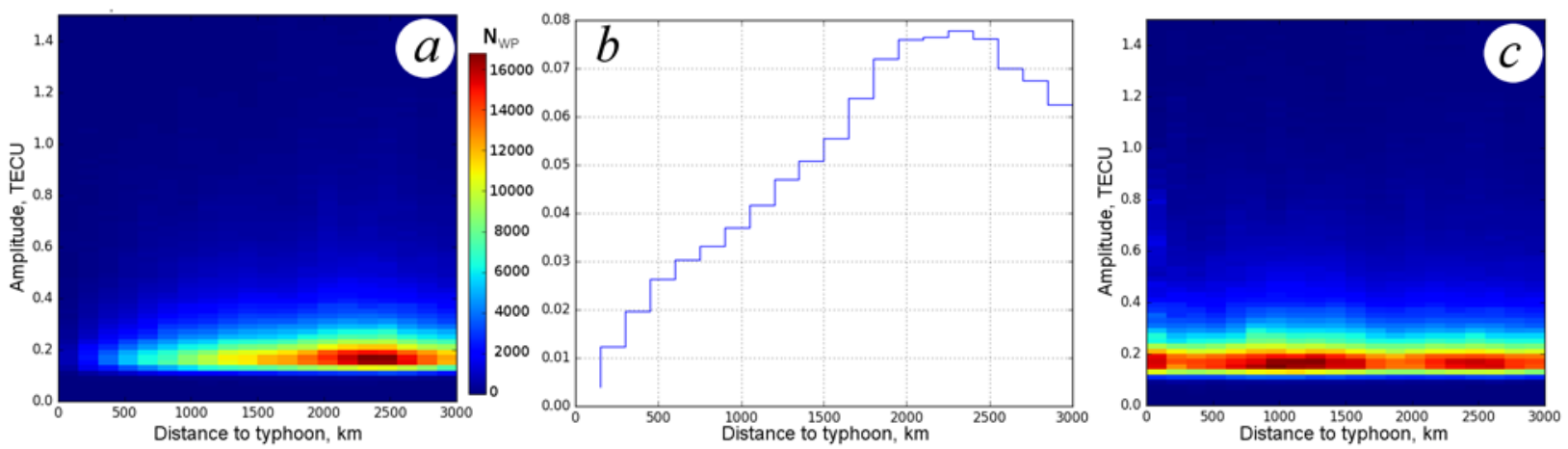

Figure 1. Normalization-free distribution of the number of TEC wave packets versus WP amplitude and distance to the TC center (a); normalized distribution of typhoon eye-station distances $(b)$; distributions of the number of WPs with respect to normalization of distances $(c)$. All the distributions were obtained for the WPs that were at a distance of $<3000 \mathrm{~km}$ from the typhoon center 
Table

Typhoons near Japan in 2008-2016

\begin{tabular}{|c|c|c|c|c|}
\hline No. & Name & Period of activity & $\begin{array}{c}V_{\max }, \text { knot } \\
\text { (date of recording) }\end{array}$ & $\begin{array}{l}\text { Number } \\
\text { of WPs }\end{array}$ \\
\hline $\mathrm{a}$ & \begin{tabular}{|c|} 
RAMMASU \\
$\mathrm{N}-08$
\end{tabular} & $\begin{array}{l}\text { May 7-13, } \\
2008\end{array}$ & 135 (May 10-11) & 5483 \\
\hline $\mathrm{b}$ & NAKRI & $\begin{array}{c}\text { May } 27 \text { - June } \\
03,2008 \\
\end{array}$ & 125 (May 29-30) & 47016 \\
\hline c & SINLAKU & \begin{tabular}{|c|} 
September 8-22, \\
2008 \\
\end{tabular} & $\begin{array}{c}125 \\
\text { ( September 11) } \\
\end{array}$ & 49711 \\
\hline d & HAGUPIT & $\begin{array}{c}\text { September } 18- \\
25, \\
2008 \\
\end{array}$ & $\begin{array}{c}120 \\
\text { (September 23) }\end{array}$ & 9359 \\
\hline e & JANGMI & \begin{tabular}{|c|} 
September $23-$ \\
October 1 \\
2008 \\
\end{tabular} & $\begin{array}{c}135 \\
\text { (September 27) }\end{array}$ & 17235 \\
\hline $\mathrm{f}$ & GUCHOL & $\begin{array}{c}\text { June 11-19 } \\
2012\end{array}$ & 130 (June 16-17) & 233390 \\
\hline g & NEOGURI & $\begin{array}{c}\text { July 3-10, } \\
2014\end{array}$ & 135 (July 07 ) & 223592 \\
\hline $\mathrm{h}$ & \begin{tabular}{|c|} 
RAMMASU \\
$\mathrm{N}-14$
\end{tabular} & $\begin{array}{c}\text { July 10-19, } \\
2014 \\
\end{array}$ & 135 (July 18) & 135585 \\
\hline i & HALONG & $\begin{array}{c}\text { July } 28- \\
\text { August } 10, \\
2014 \\
\end{array}$ & 140 (August 2-3) & 312479 \\
\hline $\mathrm{j}$ & $\begin{array}{l}\text { PHAN- } \\
\text { FONE }\end{array}$ & \begin{tabular}{|c|} 
September $28-$ \\
October 6, \\
2014 \\
\end{tabular} & 130 (October 4) & 72331 \\
\hline $\mathrm{k}$ & $\begin{array}{l}\text { VONG- } \\
\text { FONG }\end{array}$ & $\begin{array}{c}\text { October 2-14, } \\
2014\end{array}$ & $\begin{array}{c}155 \text { (October 7- } \\
\text { 8) }\end{array}$ & 93118 \\
\hline 1 & NURI & $\begin{array}{c}\text { October } 31 \text { - } \\
\text { November 6, } \\
2014\end{array}$ & $\begin{array}{c}155 \\
\text { (November 2-3) }\end{array}$ & 83216 \\
\hline $\mathrm{m}$ & LIONROCK & $\begin{array}{c}\text { August 18-30, } \\
2016\end{array}$ & 115 (August 28) & 187585 \\
\hline $\mathrm{n}$ & $\begin{array}{c}\text { NAMTHEU } \\
\mathrm{N}\end{array}$ & $\begin{array}{l}\text { August } 31- \\
\text { September 5, } \\
2016\end{array}$ & $\begin{array}{c}100 \text { (September } \\
\text { 2) }\end{array}$ & 12482 \\
\hline 0 & MERANTI & \begin{tabular}{|c|} 
September 8-16, \\
2016
\end{tabular} & $\begin{array}{c}160 \\
\text { (September 13) }\end{array}$ & 48038 \\
\hline $\mathrm{p}$ & MALAKAS & $\begin{array}{c}\text { September 11- } \\
21,2016\end{array}$ & $\begin{array}{c}115 \\
\text { (September 16) }\end{array}$ & 60641 \\
\hline
\end{tabular}

The distributions in Figure 3 show that in most cases maxima of WP number distributions occur at a distance 500-1500 km from the typhoon eye. The farthest from typhoon centers are maxima of distributions for RAMMASUN-14, HAGUPIT, and MERANTI, whose trajectories were away from Japan, as well as for NAMTHEUN and RAMMASAN-08, which had the smallest total number of recorded WPs. Presumably, insufficient amount of data acquired near the TC trajectory could also affect the distributions for these typhoons.

Some distributions demonstrate the presence of local crowdings (Figure 3, $b, e, i, l$ ). Given the lack of distinct systematics of their position on the distributions, they should probably be classed as peculiarities of typhoon movement. Typhoon eye velocities differ in some segments of trajectory, thereby the periods during which the typhoons were at different distances from Japan may vary significantly (Figure 2). So, there are segments on the trajectories along which the typhoon is moving for a few days, the distance of the typhoon center from Japan remaining virtually unchanged. In conditions of stable generation of WPs, this should give local increases in their number for certain distances, which we seem to observe.
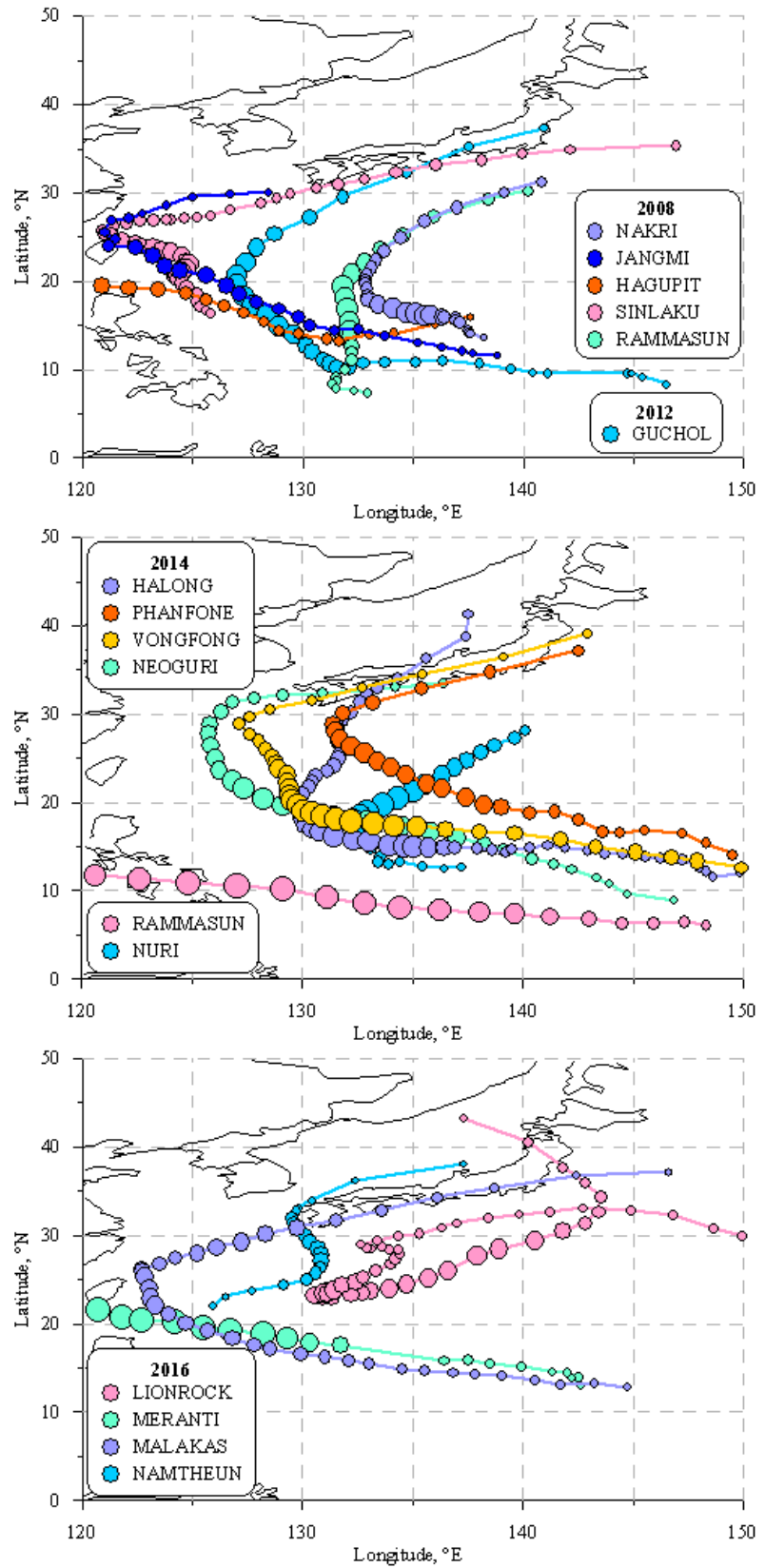

Figure 2. Typhoon trajectories in 2008-2016. The marker size is proportional to the maximum velocity of the sustained wind in TC. The diameter of the marker in the legend corresponds to the wind speed in TC equal to 100 knots

It should be emphasized that IGWs in a cyclone are excited not in its center but in the region of maximum winds, which is located in the wall of the cyclon vortex. The diameter of the vortex at a height of $10 \mathrm{~km}$ is $~ 500$ $700 \mathrm{~km}$. Thus, to observe ionospheric disturbances associated with IGWs propagating from a cyclone, the disturbances should be located at some distance, rather than above the typhoon center. Chou et al. [2017b] observed concentric TIDs that emerged during the passage of MERANTI over Taiwan; their amplitude was maximum at $500-800 \mathrm{~km}$ from the typhoon center. Thus, the distance of the observed maxima of WP number distribution from typhoon centers may indicate their possible relation to the wave disturbances excited in TCs. Note also that for several distributions WPs are detected in a 
wide range of distances to the typhoon, not in a bounded spatial region (Figure 3, $e, j, i$ ). Such even distributions of the number of WPs, weakly dependent on the distance to typhoon, point to the presence of a substantial number of WPs whose generation is independent of TC passage. Besides, as mentioned above, the difference in TC trajectories affects the type of distributions. The NEOGURI and HALONG typhoons moved to the coast of Japan most uniformly, which is also likely to affect the nature of the observed distributions; however, local maxima on these distributions are close to the TC center.

In most cases, the maximum number of wave packets is recorded near the time of the evening ST passage (point 0 on the abscissa in Figure 3). In some distribu- tions, the maximum number of WPs is observed at short distances to the typhoon in the daytime, not near the time of ST passage (Figure 3, $j-l$ ).

Further analysis shows that distributions of this type are observed for typhoons occurring in autumn. As noted above, in spring and autumn the efficiency of WP generation by the solar terminator in the ionosphere decreases considerably [Edemskiy et al., 2011]. For such typhoons we therefore observe effects related most likely not to ST but to other factors. Possible sources of WP generation are listed in [Afraimovich et al., 2003]. The ST effect on the ionosphere significantly decreases due to the weakening of the MHD resonator in this season.
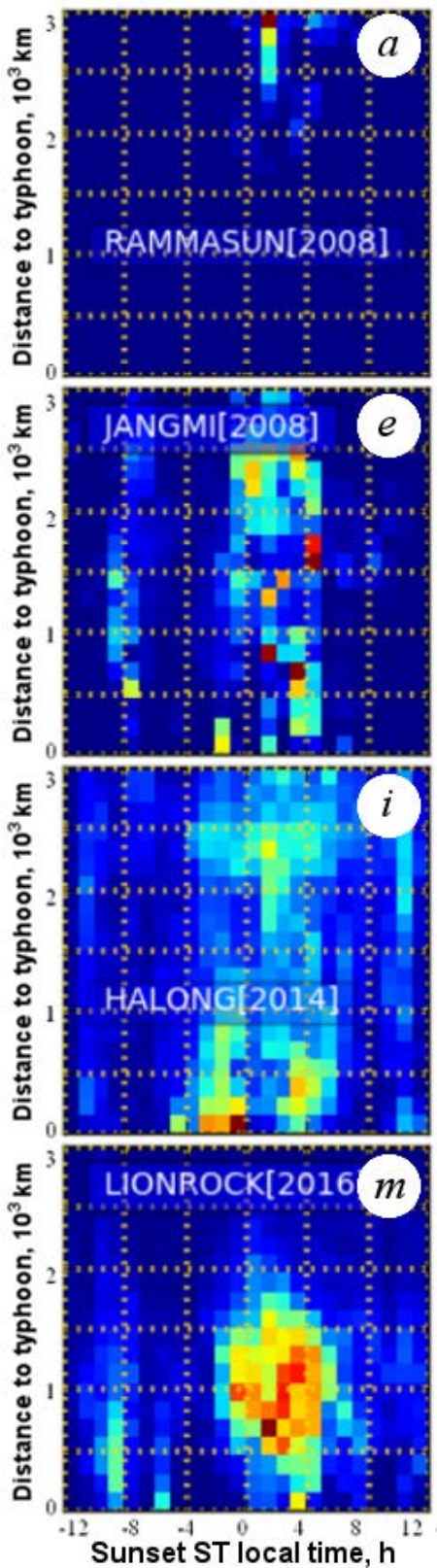
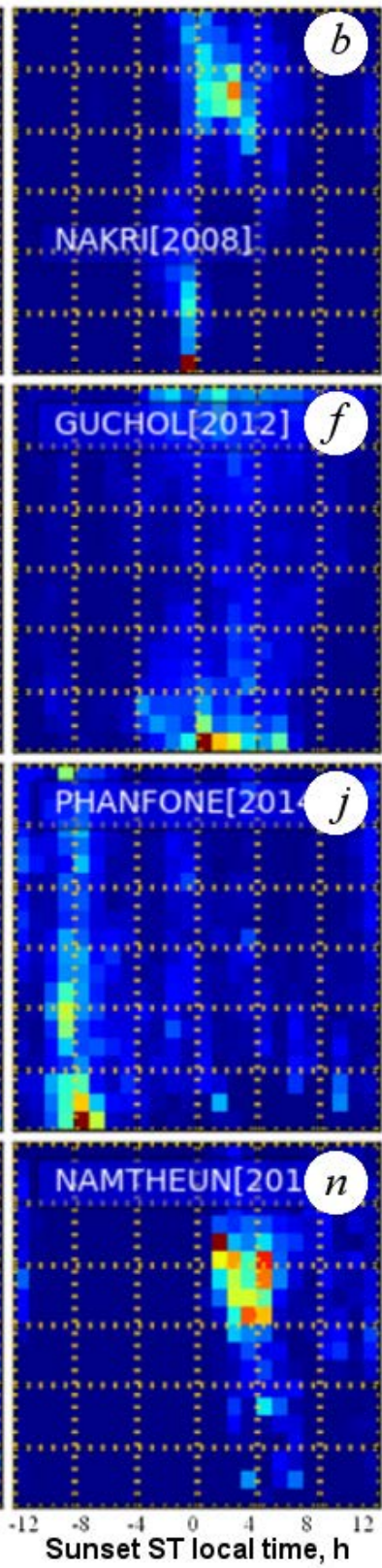
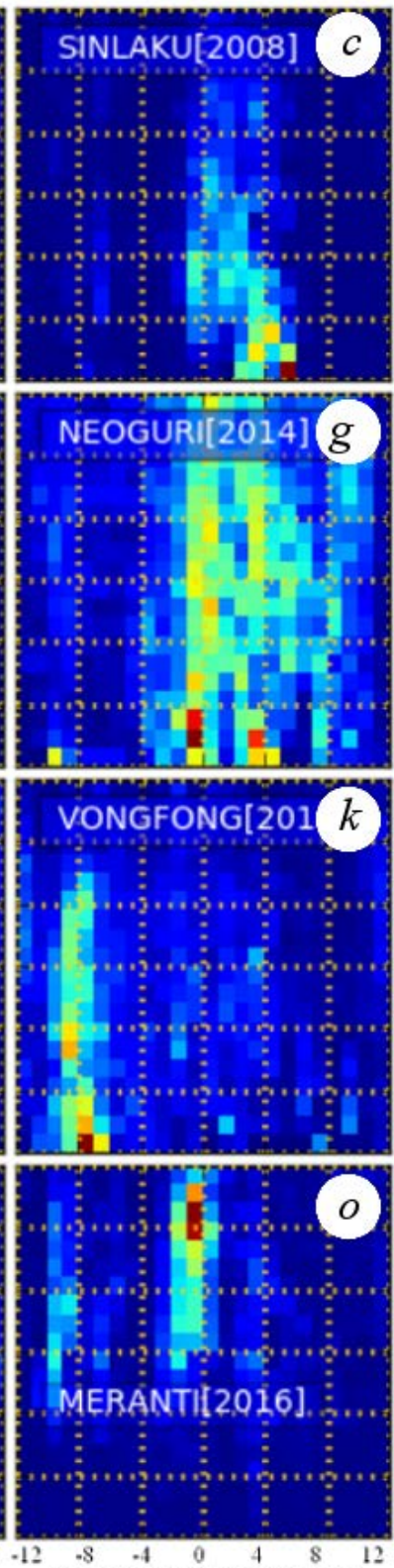

Sunset ST local time, h
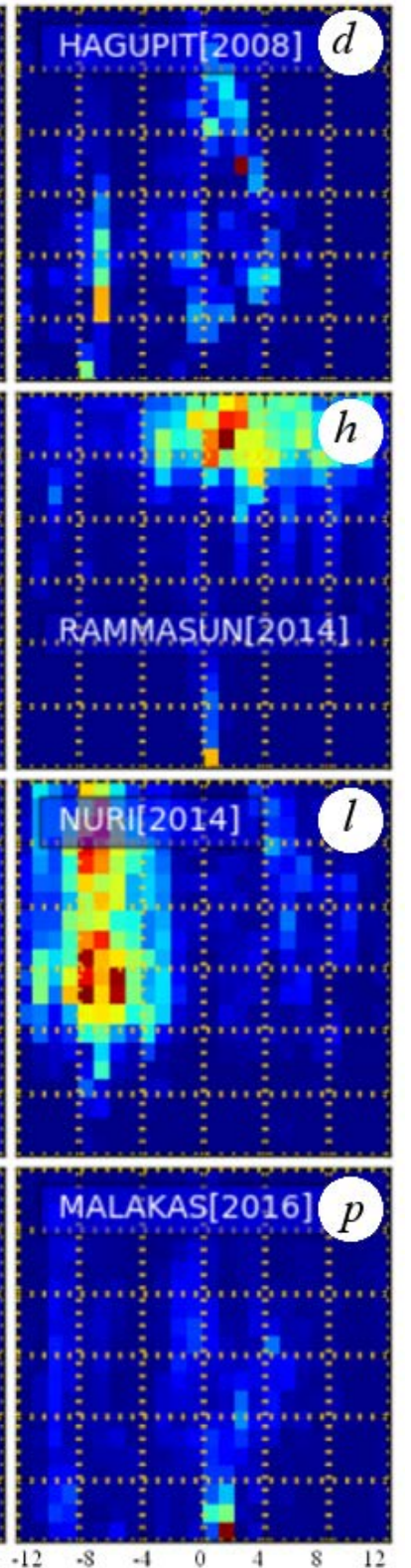

Sunset ST local time, $\mathrm{h}$

Figure 3. Normalized distributions of the number of wave packets in the local time system of the evening ST as function of the distance to the TC center 


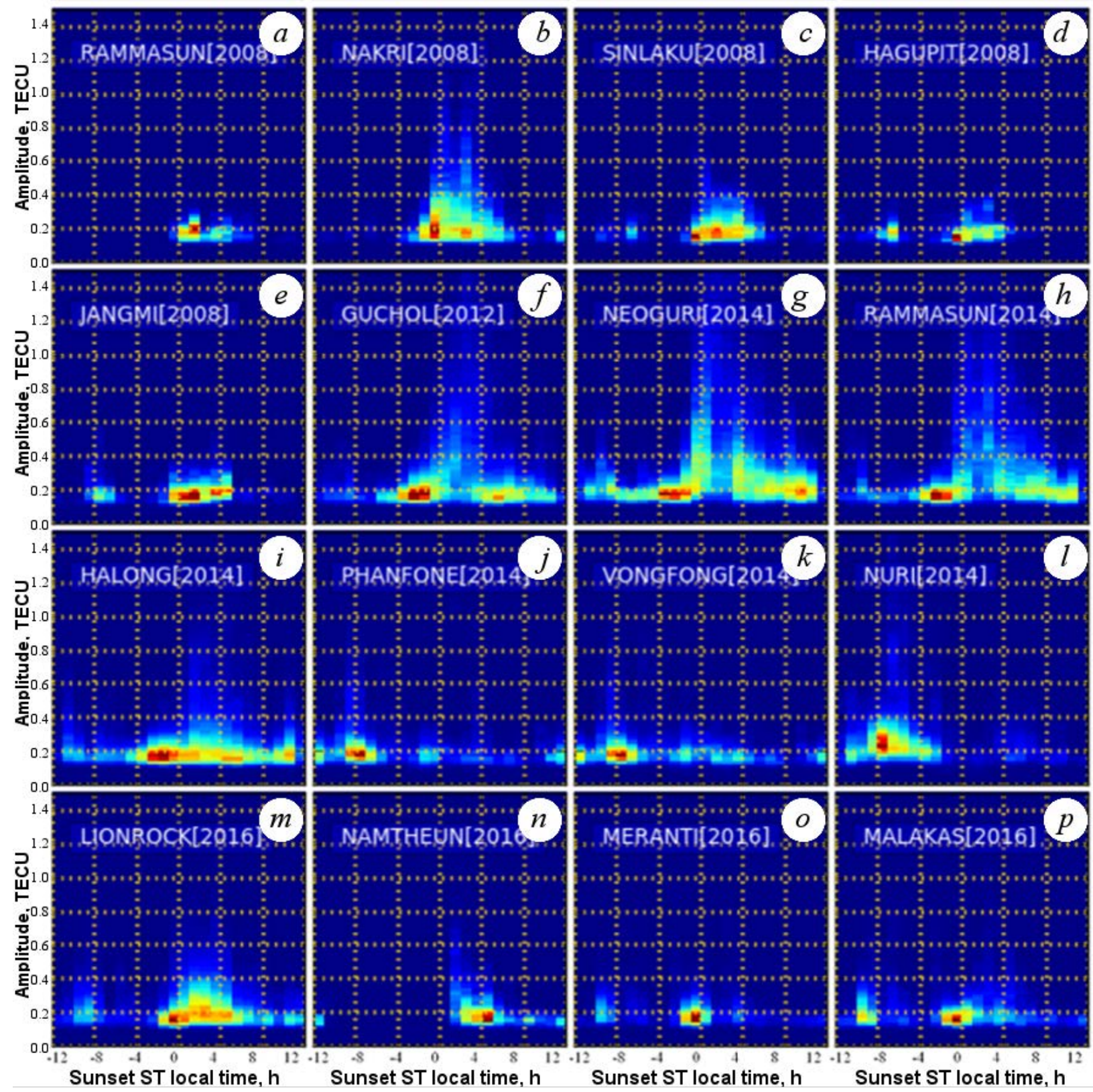

Figure 4. Normalized amplitude distributions of wave packets in the TLT system
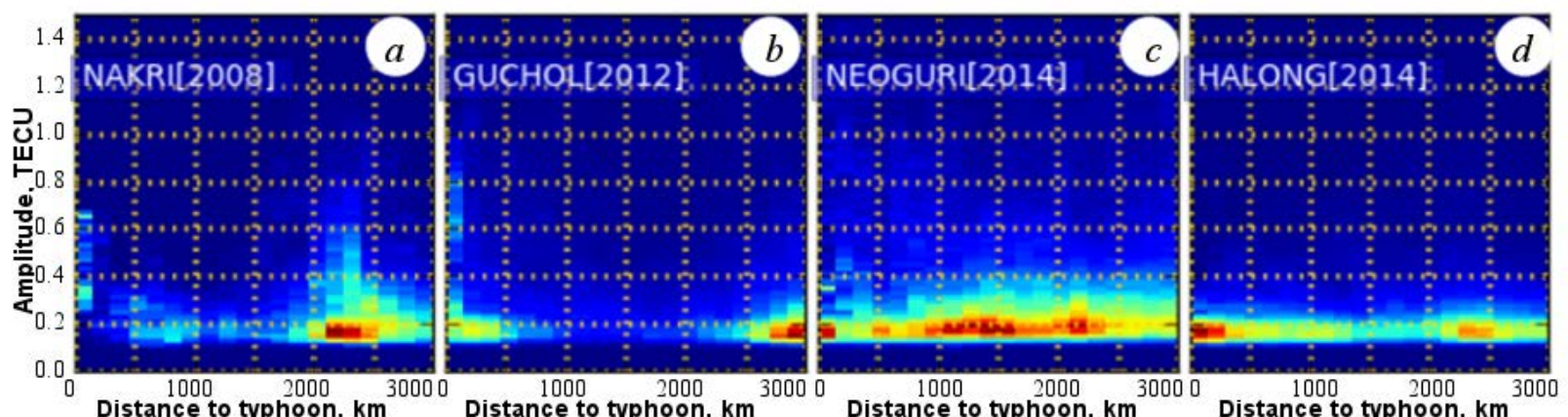

Figure 5. Normalized distributions of the number of wave packets by amplitude and distance to TC center 
Figure 4 shows WP amplitude distributions in the local time system of the evening ST. It is evident that during most typhoons WP amplitude distributions are similar, with a maximum of $\sim 0$ TLT and near $\sim 0.2-0.3$ TECU. The statistical analysis of WP parameters conducted in [Afraimovich, 2009b] yet shows that the characteristic maximum TEC amplitudes, generated by ST passage over Japan, are $0.12-0.15$ TECU during quiet periods. In addition, for some typhoons there is also a significant increase in the distribution width, i.e. there is a great number of WPs with amplitude up to 0.6-0.8 TECU $(b, f, g, h, i, m)$. At the same time, according to results of Figure 3 , the greatest number of WPs for all of these typhoons (except RAMMASUN-14) was detected at a short distance from the TC center. Thus, we can conclude that the peak WP amplitudes during the typhoons prove to be higher than the characteristic ones, and in some cases this excess is more than two times.

Notice also that some distributions demonstrate that WPs are recorded before ST passage (Figure 4, $f-i$ ). These observations were made in summer when WPs were recorded in Japan several hours before ST passage. These disturbances can be explained by the MHD hypothesis of WP generation [Leonovich et al., 2010] and by ST arrival at magnetoconjugate regions. It is seen that the registration of WPs starts several hours before ST passage and lasts throughout the night, the value variance increases during the local ST passage and returns to initial values in a few hours.

Considering that the WPs observed over Japan should be taken as a superposition of disturbances associated with the ST passage in magnetoconjugate and local regions [Edemskiy et al., 2011], it is fair to assume that TC affects the amplitude of a number of observed WPs, namely, those generated by the passage of the local ST. The return of the distributions to initial values can then be attributed to the end of local generation of WPs and to the occurrence of only MHD wave packets.

Figure 5 shows amplitude distributions of the number of WPs as function of distance to the NAKRI, NEOGURI, GUCHOL, and HALONG typhoons. During these typhoons, WP amplitudes varied within the largest range during ST passage (Figure 4). It is evident that distributions for these typhoons differ substantially both in number and in amplitude. For the NEOGURI and HALONG typhoons, the width of the amplitude distribution is practically independent of distance. For the TC GUCHOL, packets with the highest amplitude are recorded at a short distance from the typhoon; and for NAKRI, within 2000-2500 km from its center. Naturally, each TC is unique and has its own set of characteristics. The resulting distributions for each of the cases considered may be affected by a number of factors: typhoon intensity, background conditions, season, distance from a receiver network, etc. Each case therefore requires a detailed analysis, which is beyond the scope of this paper.

\section{CONCLUSION AND DISCUSSION}

The analysis of distributions of wave packet parameters in TEC during 16 intense tropical cyclones has shown that in most cases the maximum number of WPs is observed at a distance within $500-1500 \mathrm{~km}$ from typhoon centers. Maxima of distributions of the number of WPs are generally localized near the time of evening ST passage. An exception are typhoons occurring in autumn. The maximum number of WPs for them was recorded during local daylight hours. This indicates the relationship of these disturbances with other factors. Amplitude distributions of the number of WPs for all the typhoons considered are similar, with a maximum about 0.2-0.3 TECU. In half of these cases there was a significant increase in the distribution width to 0.6-0.8 TECU. Note that the increase in amplitudes of TEC wave disturbances with various periods during morning and evening hours of local time during TCs has also been discussed in [Yasyukevich et al., 2018].

This result raises the possibility of interaction of ionospheric disturbances generated by two different sources: tropical cyclones and ST passage. Afraimovich et al. [2009a] have shown that ST passage generates MHD waves in the ionosphere. Conditions of generation of these waves also depend on characteristics of the charged component of the medium in which the wave propagates [Leonovich et al., 2010]. Sharp gradients of the background electron density may cause significant changes in characteristics of the complex system of ionospheric-plasmaspheric MHD resonator, which will affect the parameters of WPs generated in this system. On the other hand, TCs produce IGWs manifesting themselves in the ionosphere as TIDs. They lead to an increase in ionospheric electron density gradients, i.e. IGWs excited in TCs can potentially serve as a source of changes in characteristics (number and intensity) of ionospheric WPs generated by ST passage.

It should also be noted that the statistical approach used in this work is not free from shortcomings because it assumes approximately equal external conditions for all the typhoons considered. In this case, trajectories of the typhoons, wind speed in them, stage of typhoon development, seasonal and heliogeomagnetic conditions, and other relevant factors in each individual case can substantially affect the conditions of generation of TEC disturbances in the form of WPs. This problem therefore requires further, more thorough analysis.

The study was performed under RFBR grant 16-3500027 and with the support of Russian President's grant MK-1097.2017.5. We have used data processing methods developed with budgetary funding of Basic Research program II-16.

We are grateful to the Geospatial Information Authority of Japan (GSI) for providing GNSS data, and to the NOAA Environmental Satellite, Data and Information Service for the data on the evolution of typhoons. We are thankful to S.V. Voeykov for his help in data processing and Yu. Yasyukevich for fruitful discussions.

\section{REFERENCES}

Afraimovich E.L., Edemskiy I.K., Leonovich A.S., Leonovich L.A., Voeykov S.V., Yasyukevich Y.V. MHD nature of night-time MSTIDs excited by the solar terminator. Geophys. Res. Let. 2009a, vol. 36, L15106. DOI: 10.1029/2009GL039803.

Afraimovich E.L., Edemskiy I.K., Voeykov S.V., Yasyukevich Yu.V., Zhivetiev I.V. Spatio-temporal structure of the wave packets generated by the solar terminator. Adv. Space Res. 2009b, vol. 44, pp. 824-835. DOI: 10.1016/j.asr.2009.05.017.

Afraimovich E.L., Perevalova N.P., Voyeikov S.V. Traveling wave packets of total electron content disturbances as deduced from global GPS network data. J. Atmosph. Solar-Terr. Phys. 2003. vol. 65, iss. 11-13, pp. 1245-1262. DOI: 10.1016/j.jastp.2003.08.007. 
Belyaev G., Boychev B., Kostin V., Trushkina E., Ovcharenko O. Modification of the ionosphere near the terminator due to the passage of a strong tropical cyclone through the large Island. Sun and Geosphere. 2015, vol. 10, pp. 31-38.

Bertin F., Testud J., Kersley L. Medium scale gravity waves in the ionospheric F-region and their possible origin in weather disturbances. Planet. Space Sci. 1975, vol. 23, pp. 493-507. DOI: 10.1016/0032-0633(75)90120-8.

Bishop R.L., Aponte N., Earle G.D., Sulzer M., Larsen M.F., Peng G.S. Arecibo observations of ionospheric perturbations associated with the passage of Tropical Storm Odette. J. Geophys. Res. 2006, vol. 111, pp. A11320. DOI: 10.1029/2006JA011668.

Chane-Ming F., Roff G., Robert L., Leveau J. Gravity wave characteristics over Tromelin Island during the passage of cyclone Hudah. Geophys. Res. Let. 2002, vol. 29, no. 6. CiteID 1094. DOI: 10.1029/2001GL013286.

Chou M.Y., Lin C. H., Yue J., Chang L. C., Tsai H.F., Chen C.H. Medium-scale traveling ionospheric disturbances triggered by Super Typhoon Nepartak (2016). Geophys. Res. Let. 2017a, vol. 44, pp. 7569-7577. DOI: 10.1002/2017GL073961.

Chou M.Y., Lin C.C.H., Yue J., Tsai H.F., Sun Y.Y., Liu J.Y., Chen C.H. Concentric traveling ionosphere disturbances triggered by Super Typhoon Meranti (2016). Geophys. Res. Let. 2017b, vol. 44, pp. 1219-1226. DOI: 10.1002/2016GL072205.

Edemskiy I.K., Voyeykov S.V., Yasyukevich Yu.V. Seasonal and latitudinal variations of parameters of wavelike MHD-based disturbances generated by solar terminator. Sovremennye problemy distantsionnogo zondirovaniya Zemli iz kosmosa [Current Problems in Remote Sensing of the Earth from Space]. 2011, vol. 8, no. 4, pp. 107-116. (In Russian).

Edemskiy I.K., Yasyukevich Y.V. Duration of wave disturbances generated by solar terminator in magnetoconjugate areas. Proc. XXXth URSI General Assembly and Scientific Symposium. Istanbul, 2011, pp. 1-4. DOI: 10.1109/URSIGASS.2011.6051003.

Forbes J.M., Palo S.E., Zhang X. Variability of the ionosphere. J. Atm. Solar-Terr. Phys. 2000, vol. 62, pp. 685-693. DOI: 10.1016/S1364-6826(00)00029-8.

Francis S. H. A theory of medium-scale traveling ionospheric disturbances. J. Geophys. Res. 1974, vol. 79, no. 34 pp. 5245-5260. DOI: 10.1029/JA079i034p05245.

Galushko V.G., Paznukhov V.V., Yampolski Y.M., Foster J.C. Incoherent scatter radar observations of AGW/TID events generated by the moving solar terminator. Ann. Geophys. 1998, vol. 16, pp. 821-827. DOI: 10.1007/s00585-998-0821-3.

Hines C.O. Internal atmospheric gravity waves at ionospheric heights. Canadian J. Phys. 1960, vol. 38, no. 11, pp. 1441-1481. DOI: $10.1139 / \mathrm{p} 60-150$.

Huang Y.N., Cheng K., Chen S.W. On the detection of acoustic gravity waves generated by typhoon by use of real time HF Doppler frequency shift sounding system. Radio Sci. 1985, vol. 20, pp. 897-906. DOI: 10.1029/RS020i004p00897.

Kazimirovsky E.S. Coupling from below as a source of ionospheric variability: a review. Ann. Geophys. 2002, vol. 45, no. 1, pp. 1-29. DOI: $10.4401 /$ ag-3482.

Kim S.-Y., Chun H.-Y., Baik J.-J. A numerical study of gravity waves induced by convection associated with Typhoon Rusa. Geophys. Res. Let. 2005, vol. 32, pp. L24816. DOI: 10.1029/2005GL024662.

Klobuchar J.A. Ionospheric time-delay algorithm for single-frequency GPS users. IEEE Trans. Aerospace and Electronics System. 1986, vol. 23, no. 3, pp. 325-331.

Kuester M.A., Alexander M.J., Ray E.A. A Model Study of Gravity Waves over Hurricane Humberto (2001). J. Atmosph. Sci. 2008. vol. 65, no. 10, pp. 3231-3246. DOI 10.1175/2008JAS2372.1.
Lastovicka J. Forcing of the ionosphere by waves from below. J. Atmos. Solar-Terr. Phys. 2006. vol. 68. pp. 479-497. DOI: 10.1016/j.jastp.2005.01.018.

Leonovich A.S., Kozlov D.A., Edemskiy I.K. Standing slow magnetosonic waves in a dipole-like plasmasphere. Planetary and Space Sci. 2010, vol. 58, no. 11, pp. 14251433. DOI: $10.1016 /$ j.pss.2010.06.007.

Medvedev A.V., Ratovsky K.G., Tolstikov M.V., Oinats A.V., Alsatkin S.S., Zherebtsov G.A. Relation of internal gravity wave anisotropy with neutral wind characteristics in the upper atmosphere. J. Geophys. Res.: Space Phys. 2017, vol. 122, pp. 7567-7580. DOI: 10.1002/2017JA024103.

Mishin E.V., Epishova A.E., Ishkova L.M., Kovalevskaya E.M., Kozlov E.F., Kolokolov L.E., Rubtsov L.N., Samorokin N.I., Sidorova L.N., Somsikov V.M., Telegin V.A., Yudovich L.A. Disturbances of F-region electron density following solar terminator during the WITS period of 16-20 March 1988. $J$. Atmosph. Terr. Phys. 1991, vol. 53, iss. 6-7, pp. 643-648. DOI: 10.1016/0021-9169(91)90091-K.

Pfister L., Chan K.R., Bui T.P., Bowen S., Legg M., Gary B., Kelly K., Proffitt M., Starr W. Gravity waves generated by a tropical cyclone during the STEP tropical field program: A case study. J. Geophys. Res. 1993, vol. 98, no. D5, pp. 8611-8638. DOI: 10.1029/92JD01679.

Polyakova A.S., Perevalova N.P. Investigation into impact of tropical cyclones on the ionosphere using GPS sounding and NCEP/NCAR Reanalysis data. Adv. Space Res. 2011, vol. 48, pp. 1196-1210. DOI: 10.1016/j.asr.2011.06.014.

Polyakova A.S., Perevalova N.P. Comparative Analysis of TEC Disturbances over Tropical Cyclone Zones in the NorthWest Pacific Ocean. Adv. Space Res. 2013, vol. 52, pp. 14161426. DOI: 10.1016/j.asr.2011.06.014.

Polyakova A.S., Yasyukevich Yu.V. Change in the intensity of ionospheric response to solar terminator passage during tropical cyclones. Proc. XXV National Conference "Radiowaves propagation" dedicated to 80 Anniversary of Domestic Investigations of Ionosphere. 2016, Tomsk, 3-9 July. 2016, vol. 1, pp. 113-166. (In Russian).

Somsikov V.M., Ganguly B. On the formation of atmospheric! inhomogeneities in the solar terminator region. J. Atmos. Terr. Phys. 1995, vol. 57, iss. 12, pp. 1513-1523. DOI: 10.1016/0021-9169(95)00014-S.

Xiao Z., Xiao S., Hao Y., Zhang D. Morphological features of ionospheric response to typhoon. J. Geophys. Res. 2007, vol. 112, pp. A04304. DOI: 10.1029/2006JA011671.

Zakharov V.I., Kunitsyn V.E. Regional features of atmospheric manifestations of tropical cyclones according to ground-based GPS network data. Geomagnetism and Aeronomy. 2012, vol. 52, no. 4, pp. 533-545. DOI: 10.1134/S0016793212040160.

Yasyukevich Yu.V., Perevalova N.P., Edemskiy I.K., Polyakova A.S. Otklik ionosfery na gelio- i geofizicheskie vozmushchayushchie factory po dannym GPS [Ionosphere response to helio- and geophysical disturbing factors from GPS data]. Irkutks: Irkutsk State University Publ., 2013, 271 p. (In Russian).

Yasyukevich A.S., Padokhin A.M., Mylnikova A.A., Yasyukevich Yu.V., Voyeikov S.V., Tereshin N.A. Changes in the intensity of TEC variations with different time scales during tropical cyclones. Uchenye zapiski fizicheskogo fakul'teta $M G U$ [Memoirs of the Faculty of Physics, Lomonosov Moscow State University], 2018, no. 3, pp. 1830901. (In Russian).

http://rammb.cira.colostate.edu

http://terras.gsi.go.jp

How to cite this article

Edemskiy I.K., Yasyukevich A.S.. Observing wave packets generated by solar terminator in TEC during typhoons Solar-Terrestrial Physics. 2018. vol. 4, iss. 2, pp. 33-40. DOI: 10.12737/stp-42201806 